\title{
Management of Sexual Maturation and Natural Spawning of Captive- Reared Yellowtail Kingfish, Seriola lalandi, in an Indoor Rearing Tank
}

\author{
Sang Geun Yang ${ }^{1}$, Seung Cheol Ji ${ }^{1}$, Sang Gu Lim ${ }^{1}$, Sang Woo Hur ${ }^{2}$, Minhwan Jeong ${ }^{1}$, \\ Chi Hoon Lee ${ }^{2}$, Bong Seok Kim ${ }^{1}$ and ${ }^{\dagger}$ Young-Don Lee ${ }^{2}$ \\ ${ }^{1}$ Jeju Fisheries Research Institute, National Institute of Fisheries Science, Jeju 63610, Korea \\ ${ }^{2}$ Marine Science Institute, Jeju National University, Jeju 63333, Korea
}

\begin{abstract}
This study describes results on sexual maturation and characteristics of natural spawned eggs to develop a method for the production of stable, healthy fertilized eggs from captive-reared yellowtail kingfish, Seriola lalandi. A total of 59 yellowtail kingfish were captured off the coast of Jeju Island, after which the broodstock was cultured in indoor culture $\operatorname{tank}\left(100 \mathrm{~m}^{3}\right)$ until they were $6.1-14.9 \mathrm{~kg}$ in body weight. As part of the rearing management for induced sex maturation, the intensity of illumination was maintained at 130 lux. The photoperiod (light/dark; L/D) was set to a $12 \mathrm{~L} / 12 \mathrm{D}$ from October 2013 to January 2014, and 15 L/9 D from February 2014 to June 2014. Feeds comprised mainly EP (Extruded Pellets), with squid cuttlefish added for improvement of egg quality, and was given from April to June 2014. The first spawning of yellowtail kingfish occurred in May 3, 2014, at a water temperature of $17.0^{\circ} \mathrm{C}$. Spawning continued until June 12, 2014, with the water temperature set at $20.5^{\circ} \mathrm{C}$. Time of spawning was 26 times at this period. The total number of eggs that spawned during the spawning period was $4,449 \times 10^{3}$. The buoyant rate of spawning eggs and fertilization rate of buoyant eggs during the spawned period were $76.1 \%$ and $100 \%$, respectively. The diameters of the egg and oil globule were $1.388 \pm 0.041 \mathrm{~mm}$ and $0.378 \pm 0.029 \mathrm{~mm}$, respectively, which was higher in early eggs than in those from late during the spawned period.
\end{abstract}

Key words : Yellowtail kingfish, Seriola lalandi, Induction sexual maturation, Natural spawning, Fertilization rate of buoyant eggs

\section{INTRODUCTION}

Three species of yellowtail (Seriola spp.) inhabit the coasts of South Korea - the yellowtail kingfish (S. lalandi), yellowtail ( $S$. quinqueradiata), and greater amberjack ( $S$. dumerili) (Kim et al., 2001). Yellowtail kingfish do not only occur in South Korea, however, but also in temperate waters worldwide, including Japan and China (NFRDI, 2004). In Japan, 3 species of $S$. lalandi, S. quinqueradiata and $S$. dumerili are cultivated (Nakada, 2000). Yellowtail kingfish are also cultivated in Australia and New Zealand (Moran et al., 2007; Kolkovski \& Sakakura, 2007), as well as in California, USA (Stuart \& Drawbridge, 2012).

Aquaculture of Seriola spp. in South Korea has been attempted, beginning with pond culture of yellowtail in 1963. This operation was, however, suspended because it was not economically viable. Since then, there was an experimental culture with juvenile yellowtail captured off

\footnotetext{
Manuscript received May 20, 2016, Received in revised form May 28, 2016, Accepted June 07, 2016

${ }^{\dagger}$ Corresponding Author: Young-Don Lee, Marine Science Institute, Jeju National University, Jeju 63333, Korea. Tel. : +82-64-782-8922, Fax : +82-64783-6066, E-mail: leemri@jejunu.ac.kr

This is an Open Access article distributed under the terms of the Creative Commons Attribution Non-Commercial License (http:// creativecommons.org/licenses/by-nc/3.0) which permits unrestricted non-commercial use, distribution, and reproduction in any medium, provided the original work is properly cited.
} 
the south coast. There was also active cultivation of captured juveniles for export to Japan. After the export of captured seeds for cultivating was banned in South Korea in 1976, pond culture of yellowtail began in earnest. However, domestic aquaculture of Seriola spp. has so far been restricted to a method of pond culture of captured juveniles. In the future, culture production systems, such as seed production and intermediate rearing, need to be developed for the management of broodstock. According to Article 6, Clause 2 of the 'Enforcement Decree of the Fishery Resources Management Act' (Prohibition of Capturing and Gathering of Fishery Resources - Weight and Length, Presidential Decree No. 25276), implemented from early 2014, it restricts the capture of yellowtail to individuals of $30 \mathrm{~cm}$ or shorter.

In Japan, the aquaculture of yellowtail kingfish used hormones for the induction of maturation and production of fertilized eggs (Fugita \& Yogata, 1984). However, there has been no research into reproductive biology for the cultivation of yellowtail kingfish in South Korea. This study therefore aimed to develop a method for the production of stable, healthy fertilized eggs from yellowtail kingfish. Since yellowtail kingfish are spring-summer spawning fish, that typically spawn April to June, broodstock management was conducted by controlling the light cycle in an indoor tank using the characteristics of spring-summer spawning, during which the spawning behavior, spawning induction, and spawning frequency were examined. In addition, the spawning amount, buoyancy rate and fertilization rate among spawned eggs, the size change of egg and oil droplet for buoyant eggs were investigated.

\section{MATERIALS AND METHODS}

Fifty-nine adult yellowtail kingfish were caught off the coast of Jeju, South Korea, and raised in a concrete indoor tank $\left(8.0 \times 8.0 \times 2.0 \mathrm{~m}\right.$, usable capacity $\left.100 \mathrm{~m}^{3}\right)$. In all, 20 fish $(4.5 \pm 0.7 \mathrm{~kg})$ were raised in March 2008, while the

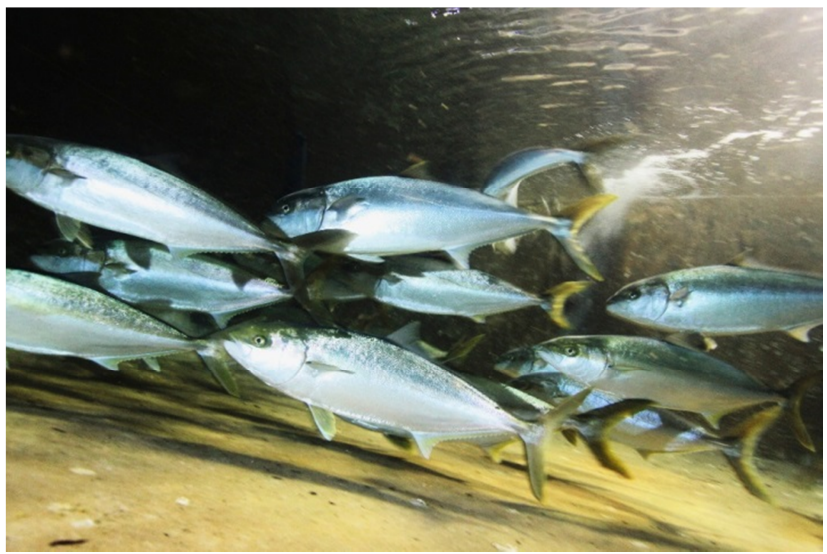

Fig. 1. Rearing management for the induced sexual maturation of captive-reared yellowtail kingfish ( $S$. lalandi) broodstock in indoor culture tank

remaining 39 fish $(2.6 \pm 0.7 \mathrm{~kg})$ were raised in October 2012 (Fig. 1). The tank was filled with natural seawater, with the flow rate set at 6 cycles per day. The water temperature during the breeding period ranged from 12.0 to $29.0^{\circ} \mathrm{C}$. During the spawning season, the flow rate was adjusted to 3.5 cycles per day to protect the eggs, thus enabling good quality fertilized eggs to be collected. To induce maturation, a light intensity of 130 Lux was maintained, in accordance with conditions for inducing maturation in spring-summer spawning fish (Song, 2013), a light cycle of $12 \mathrm{~h}$ Light (L): $12 \mathrm{~h}$ Dark (D) was used from October 2013 to January 2014, and a light cycle of 15 h L: $9 \mathrm{~h} \mathrm{D}$ from February 2014 to the end of spawning. Fish were fed a commercial EP feed (16-18 mm), comprising $\geq$ $46.0 \%$ crude protein, $\geq 9.0 \%$ crude lipid, $\leq 16.0 \%$ crude ash, $\leq 5.0 \%$ crude fiber, $\geq 1.0 \%$ calcium, and $\leq 2.7 \%$ phosphorus. From April to the end of spawning, feeds were supplemented with Pacific flying squid (Todarodes pacificus).

Spawning began after sunset, between 19:00 and 24:00, and ended between 02:00 and 03:00. Eggs were collected every morning between 08:00 and 09:00, before separating the buoyant eggs and sunken eggs using a measuring cylinder. The volume of each group was measured to 
calculate the spawning amount, while the buoyancy rate was calculated from the ratio of buoyant eggs to total spawning amount. The number of eggs was calculated volumetrically using a conversion rate of 500 eggs per $\mathrm{mL}$.

To calculate the rate of fertilization, a profile projector (PJ300, Mitutoyo) was used to count the ratio of buoyant eggs showing signs of development. The egg diameter and oil droplet diameter for 30 buoyant eggs were measured to a precision of $0.001 \mathrm{~mm}$ at 1-week intervals, using the profile projector.

\section{RESULTS}

\section{Growth of broodstock}

The growth of the broodstock in the concrete indoor tank during the breeding period is displayed in Table 1 and Fig. 2. Those individuals acquired in March 2008, grew from $3.1-5.9 \mathrm{~kg}$ (mean $4.5 \pm 0.7 \mathrm{~kg}$ ) to $9.4-14.9 \mathrm{~kg}(11.4 \pm$ $1.3 \mathrm{~kg}$ ) in 77 months. Individuals acquired in October 2012 grew from $1.3-4.0 \mathrm{~kg}(2.6 \pm 0.9 \mathrm{~kg})$ to $6.1-10.5 \mathrm{~kg}$ $(8.0 \pm 1.1 \mathrm{~kg})$ in 22 months. Males and females could not be distinguished owing to the similarity of their external appearance.

\section{Spawning behavior}

Following 3 months of long-day conditions (15L:9D), the spawning of yellowtail kingfish began in early May
2014 , between the times of 19:00 and 24:00. While the fish were swimming together in an orderly manner near the edges of the tank, a relatively large female was seen being followed by 2 males, twisting and intertwining. The males stuck close to the female's genital pore while swimming rapidly, and applied pressure to the female's abdomen. After approximately 1 hour of courtship behavior, the female began spawning, and the orderly swimming of males became started to spawn, in a frenzy of circling activity. After a while, the clear and still water in the tank became clouded with the spawned eggs and the sperm of the males, while small bubbles rose to the surface of the water.

\section{Spawning amount}

Spawning first began on May 3, when the water temperature was $17.0^{\circ} \mathrm{C}$, and it ended in mid-June, when the temperature was $20.5^{\circ} \mathrm{C}$. The yellowtail kingfish undergoing rearing management spawned a total of 26 times during the spawning period, with the total spawning amount being $4,449 \times 10^{3}$ individuals, making it an average spawning amount of $171 \times 10^{3}$ each time. Among mature yellowtail kingfish eggs, the mean ratio of buoyant eggs was $76.1 \%$, while the fertilization rate for buoyant eggs during the spawning period was $100 \%$ (Fig. 3). Right up until the third spawning event, the majority of eggs were cloudy or sunken, with a buoyancy rate of $0 \%$. From May 23 to the end of spawning, the fish exhibited a pattern of spawning

Table 1. Growth of captive-reared yellowtail kingfish (S. lalandi) broodstock used for the induction of sexual maturation and natural spawning in an indoor culture tank

\begin{tabular}{|c|c|c|c|c|c|}
\hline \multirow{3}{*}{ Rearing period } & \multirow{3}{*}{$\begin{array}{c}\text { Ind. } \\
\text { number }\end{array}$} & \multicolumn{4}{|c|}{ Size } \\
\hline & & \multicolumn{2}{|c|}{ Total length $(\mathrm{cm})$} & \multicolumn{2}{|c|}{ Weight (kg) } \\
\hline & & First & Final & First & Final \\
\hline $\begin{array}{c}\text { 2008. 3-2014. } 7 \\
\text { (77 months) }\end{array}$ & 20 & $\begin{array}{c}65.9-80.8 \\
(74.3 \pm 4.4)\end{array}$ & $\begin{array}{c}96.0-114.0 \\
(104.8 \pm 5.3)\end{array}$ & $\begin{array}{c}3.1-5.9 \\
(4.5 \pm 0.7)\end{array}$ & $\begin{array}{c}9.4-14.9 \\
(11.4 \pm 1.3)\end{array}$ \\
\hline $\begin{array}{l}\text { 2012. 10-2014. } 7 \\
\quad(22 \text { months })\end{array}$ & 39 & $\begin{array}{c}52.0-79.0 \\
(65.5 \pm 8.3)\end{array}$ & $\begin{array}{c}85.0-103.0 \\
(93.8 \pm 4.2)\end{array}$ & $\begin{array}{c}1.3-4.0 \\
(2.6 \pm 0.9)\end{array}$ & $\begin{array}{c}6.1-10.5 \\
(8.0 \pm 1.1)\end{array}$ \\
\hline
\end{tabular}




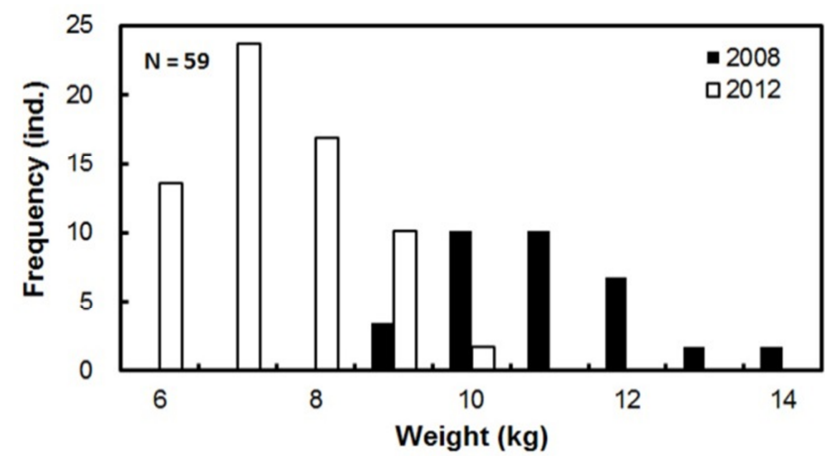

Fig. 2. Weight of captive-reared yellowtail kingfish ( $S$. lalandi) broodstock used for the induction of sexual maturation and natural spawning in 2014. - 2008, wild-caught broodstock in 2008; $\square$ 2012, wild-caught broodstock in 2012 .

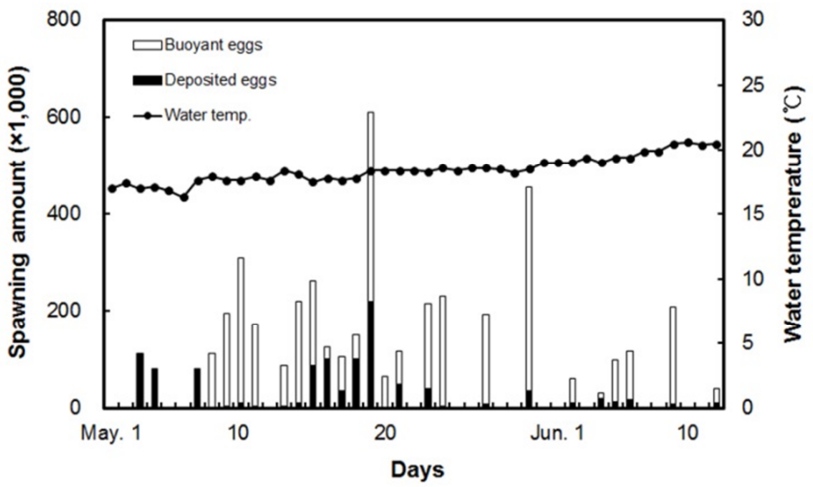

Fig. 3. Spawn frequency and egg production of captivereared yellowtail kingfish $(S$. lalandi) broodstock in an indoor culture tank from May to June, 2014.

at 2-3 day intervals, with the buoyancy rate ranging from $33.3-96.4 \%$.

\section{Fertilized eggs}

The egg diameter of fertilized yellowtail kingfish eggs was $1.388 \pm 0.041 \mathrm{~mm}$, during which those eggs were buoyant with a single oil globule (Fig. 4). During the spawning period, the egg diameter changed from $1.416 \pm 0.030 \mathrm{~mm}$ at the start of spawning on May 8, to $1.351 \pm 0.037 \mathrm{~mm}$ at the end of spawning on June 9.

The oil globule diameter at the start of spawning (May 8) was $0.348 \pm 0.025 \mathrm{~mm}$, which gradually decreased towards the end of the spawning period. The egg diameter and oil

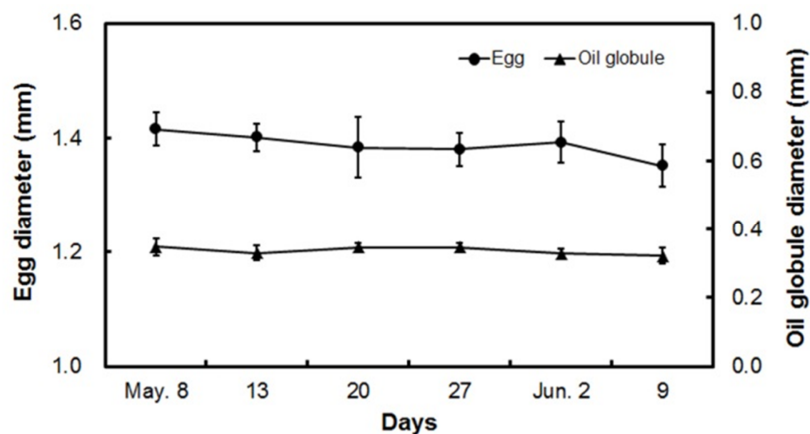

Fig. 4. Changes in mean egg diameter and oil globule diameter of natural spawned eggs from captivereared yellowtail kingfish (S. lalandi) broodstock in 2014.

globule diameter were reduced at the end of spawning by $4.1 \%$ and $13.0 \%$, respectively, from that at the start of spawning.

\section{DISCUSSION}

In broodstock management and rearing management for the induction of spawning in indoor tanks, it is important for the size and shape of the tank to be suited to the swimming characteristics and spawning behaviors of the broodstock. In previous studies, a $140-\mathrm{m}^{3}$ circular tank was used for California yellowtail (Seriola lalandi) (Stuart and Drawbridge, 2012), while spawning was induced in 14 yellowtail kingfish (mean weight, $17 \mathrm{~kg}$ ) in a $70-\mathrm{m}^{3}$ circular tank (Moran et. al., 2007). In this study, the size of the tank was $100 \mathrm{~m}^{3}$. The fish acquired in March 2008 grew from in mass from a mean of $4.5 \pm 0.7 \mathrm{~kg}$ to $11.4 \pm$ $1.3 \mathrm{~kg}$ in 77 months, while the fish acquired in October 2012 grew from $2.6 \pm 0.9 \mathrm{~kg}$ to $8.0 \pm 1.1 \mathrm{~kg}$ in 22 months. By adjusting the light cycle, we were able to induce spawning and retrieve fertilized eggs. In determining the size of broodstock management tanks for Seriola spp., it was assumed that there is some relationship between broodstock density and spawning behavior characteristics. Since this was the first time that fertilized eggs had been produced by yellowtail kingfish broodstock in an indoor 
tank, future studies will be required for the development of a breeding tank system that accounts for spawning behavior characteristics and the optimal male-to-female ratio and breeding density for stable healthy egg production.

In New Zealand yellowtail kingfish, spawning occurred 30-90 minutes after courtship, but another male was observed to participate 10-15 minutes prior to spawning (Moran et al, 2007). In this study, we also observed 2 males entwining and twisting as they followed a single large female, sticking close to the genital pore, and swimming rapidly while pressing the abdomen of the female to induce spawning. Having information about the pre-spawning courtship behavior makes it possible to predict when spawning will occur and prepare for egg collection, thereby reducing the risk of bacterial infection due to delayed collection and mechanical damage from the collecting net (Moran et al, 2007).

During this study, in which light cycle regulation was used to induce maturation of yellowtail kingfish in an indoor tank, spawning commenced in early May, when the water temperature was $17.0^{\circ} \mathrm{C}$. It continued until mid-June, when the water temperature was over $20^{\circ} \mathrm{C}$. It is difficult to find instances of broodstock management with light cycle-induced maturation of spring-summer spawning yellowtail kingfish off the coast of Jeju; however, sevenband groupers (Epinephelus septemfasciatus), which are summer spawning fish inhabiting the Jeju region, undergo induction of maturation and fertilized egg production under similar broodstock management conditions of long days with water temperature regulation (Song, 2013).

Yellowtail kingfish fertilized egg production in Goto in the south of Japan was conducted with hormone treatment between April and May at a water temperature of 15.5$18.5^{\circ} \mathrm{C}$, followed by artificial insemination (Fugita \& Yogata, 1984). California yellowtail in California, San Diego, and Catalina Island spawn between April and July at water temperatures of $16.5-22.0^{\circ} \mathrm{C}$, while yellowtail kingfish inhabiting East Coast in northern New Zealand spawn between November and February, when the water temperature is at least $17.0^{\circ} \mathrm{C}$ (Stuart \& Drawbridge, 2012; Moran et al., 2007).

In terms of the size of individuals participating in spawning, one study of gonadal development in yellowtail kingfish reported that the minimum size fork length of females reaching maturity was $78 \mathrm{~cm}, 50 \%$ of females reached maturity at $94 \mathrm{~cm}$, and $100 \%$ of females reached maturity at $128 \mathrm{~cm}$. The minimum size of males at maturity was 75 $\mathrm{cm}$. In all, $50 \%$ of males reached maturity at $81 \mathrm{~cm}$, and $100 \%$ of males reached maturity at $93 \mathrm{~cm}$ (Poortenaar et al., 2001). Another study in New South Wales, Australia, showed that females first matured at 3 years and a fork length of $70 \mathrm{~cm}$, and that $50 \%$ reached maturity at $83 \mathrm{~cm}$ between $4-5$ years. The males matured at 1 year and $30 \mathrm{~cm}$. In all, $50 \%$ of males matured at $47 \mathrm{~cm}$ and 1 year (Gillanders et al., 1999a, b). McKenzie et al. (2014) reported that the reason why yellowtail kingfish living in New South Wales and New Zealand reach maturity and different sizes and ages is the water temperature, the unique habits of individuals, and the differences in the habitat conditions. In this study, the yellowtail kingfish broodstock were caught in the wild, and bred to a length of 85.0-103.0 cm (mean 97.8 $\pm 7.0 \mathrm{~cm}$ ) in an indoor tank, meaning that, in contrast to the study of gonadal development in yellowtail kingfish off the coast of northern New Zealand, the females should have exceeded the length at which they first started reaching maturity, while the males would have reached $100 \%$ maturity.

A previous study showed that California yellowtails spawn 37-43 times in water temperatures ranging from 16.5-22. $0^{\circ} \mathrm{C}$ (Stuart \& Drawbridge, 2012). In the present study, yellowtail kingfish spawned 26 times in water temperatures of $17.0-20.5^{\circ} \mathrm{C}$. This is consistent with results from southern Japan, California, and New Zealand, which showed that spawning begins at temperatures of $15^{\circ} \mathrm{C}$ and above, but the regional differences in the number of 
spawns and the end of spawning can be considered to result from adaptive physiological characteristics.

Fugita \& Yogata (1984) reported a fertilization rate of $81.6 \%$ for artificial insemination in yellowtail kingfish, while natural spawning by yellowtail kingfish in an indoor tank exhibited a fertilization rate of over $99 \%$ for buoyant eggs (Moran et al., 2007). In this study, the buoyancy rate was $76.1 \%$, while the fertilization rate of buoyant eggs was 100\%. Fugita \& Yogata (1984) measured the egg diameter and oil globule diameter of yellowtail kingfish that had been artificially inseminated following hormone treatment, and reported diameters of $1.36 \pm 0.07 \mathrm{~mm}$ and $0.34 \pm 0.02$ $\mathrm{mm}$, respectively. In this study, the egg diameter and oil globule diameter of yellowtail kingfish after natural spawning were $1.388 \pm 0.041 \mathrm{~mm}$ and $0.0378 \pm 0.029 \mathrm{~mm}$, showing slightly greater size than that observed following artificial insemination. The egg diameter and oil globule diameter of California yellowtail were reported at $1.36 \pm 0.03 \mathrm{~mm}$ and $0.29 \pm 0.02 \mathrm{~mm}$ in 2009 , and $1.40 \pm 0.05 \mathrm{~mm}$ and $0.32 \pm$ $0.05 \mathrm{~mm}$ in 2010 (Stuart \& Drawbridge, 2012). Another study found that the egg diameter and oil globule diameter in yellowtail kingfish were $1.40 \pm 0.04 \mathrm{~mm}$ and $0.31 \pm 0.01$ $\mathrm{mm}$, respectively (Moran et al., 2007). The egg diameters in California yellowtail and yellowtail kingfish were similar. In this study, the egg diameter and oil globule diameter changed over during the course of spawning season, showing reductions of $4 \%$ and $13 \%$, respectively, at the end of spawning from those at the start of spawning. The decrease in oil globule diameter size over the course of the spawning season also tended to follow the change in egg diameter. These results show that the egg diameter in yellowtail kingfish decreases volumetrically by approximately $15 \%$ during the spawning season, and that the oil globule diameter is closely related to the egg diameter and tends to decrease in size more than the egg diameter, resulting in a reduction in oil globule volume of approximately $20 \%$ from that at the start of spawning (Moran et al., 2007). The reasons for this reduction in egg diameter include differences between females in egg production and spawning period (Fugita \& Yogata, 1984), as well as the general reduction in egg quality as the spawning period continues (Brooks et al., 1997). However, although egg quality is assumed to be better for larger eggs (Kamler, 1992), there was no noticeable trend during the spawning period. It was therefore difficult to draw any conclusions about whether or not egg diameter affects egg quality (Moran et al, 2007). Although this protocol produced fertilized eggs, future studies will be required investigating management to improve the health of broodstock for the stable acquisition of healthy eggs.

\section{ACKNOWLEDGMENTS}

This study was conducted as part of the National Institute of Fisheries Science' Fisheries Research Project to develop technologies for the commercialization of yellowtail farming (R2016008).

\section{REFERENCES}

Brooks S, Tyler CR, Sumpter JP (1997). Egg quality in fish: What makes a good egg? Rev Fish Biol Fish 7: 387-416.

Fugita S, Yogata T (1984) Induction of ovarian maturation, embryonic development and larvae and juveniles of the amberjack, Seriola aureovittata. Japanese J Ichthyol 30: 426-434.

Gillanders BM, Ferrell DJ, Andrew NL (1999a) Ageing methods for yellowtail kingfish, Seriola lalandi, and results from age- and size-based growth models. Fish Bull 97:812-827.

Gillanders BM, Ferrell DJ, Andrew NL (1999b) Size at maturity and seasonal changes in gonad activity of yellowtail kingfish (Seriola lalandi; Carangidae) in New South Wales, Australia. New Zealand J Mar Freshwater 
Res 33:457-468.

Kamler E (1992) Early Life History of Fish: An Energetics Approach. Chapman and Hall, New York.

Kim IS, Choi Y, Kim BJ (2001) Percoidei fishes of Korea. Korea Research Institute of Bioscience and Biotechnology Korea. pp. 279.

Kolkovski S, Sakakura Y (2007) Yellowtail kingfish, from larvae to mature fish-problems and opportunities. World Aquac 38:44-48.

McKenzie J, Smith M, Watson T, Francis M, Ó Maolagáin C, Poortenaar C, Holdsworth J (2014) Age, growth, maturity and natural mortality of New Zealand kingfish (Seriola lalandi lalandi). New Zealand Fish Assessment Report, pp 1-38.

Moran D, Smith CK, Gara B, Poortenaar CW (2007) Reproductive behaviour and early development in yellowtail kingfish (Seriola lalandi Valenciennes 1833). Aquaculture
262:95-104.

Nakada M (2000) Yellowtail and related species culture. In: Stickney RR (ed.), Encyclopedia of Aquaculture. John Wiley \& Sons, Inc., New York, pp 1007-1036.

NFRDI (2004) Commercial fishes of the coastal \& offshore waters in Korea. pp 162.

Poortenaar CW, Hooker S, Sharp N (2001) Assessment of yellowtail kingfish (Seriola lalandi lalandi) reproductive physiology, as a basis for aquaculture development. Aquaculture 201:271-286.

Song YB (2013). Effect of water temperature and salinity on the fertilized egg development and larval development of sevenband grouper, Epinephelus septemfasciatus. Dev Reprod 17:369-377.

Stuart K, Drawbridge M (2012) Spawning and larval rearing of California Yellowtail (Seriola lalandi) in Southern California. Bull Fish Res Agen 35:15-21. 